\title{
Effects of chronic administration of tamsulosin and tadalafil, alone or in combination, in rats with bladder outlet obstruction induced by chronic nitric oxide deficiency
}

Rommel Prata Regadas ${ }^{1}$, Ricardo Reges ${ }^{1}$, João Batista Gadelha Cerqueira ${ }^{1}$, Daniel Gabrielle Sucupira ${ }^{1}$, Francisco Vagnaldo F. Jamacaru², Manoel Odorico de Moraes², Lúcio Flávio Gonzaga-Silva ${ }^{1}$

${ }^{1}$ Division of Urology and ${ }^{2}$ Department of Pharmacology, Universidade Federal do Ceara, CE, Brazil

\section{ABSTRACT}

Purpose: The aim of this study was to define if tadalafil causes detrusor muscle impairment and to observe the effect of combination of tadalafil with tamsulosin on the lower urinary tract of rats with bladder outlet obstruction (B00) induced by chronic nitric oxide deficiency.

Materials and Methods: Thirty-one male rats were randomized to following groups: 1 - control; 2 - L-Nitroarginine methyl ester (L-NAME); 3 - Tamsulosin + L-NAME, 4 Tadalafil+L-NAME; and 5 - Tamsulosin + Tadalafil + L-NAME. At the end of the treatment period (30 days), all animals were submitted to urodynamic study.

Results: The administration of L-NAME increased the number of non-voiding contractions (NVC) $(1.04 \pm 0.22)$, volume threshold (VT) $(1.86 \pm 0.35)$, and micturition cycle (MC) $(1.34 \pm 0.11)$ compared with control $(0.52 \pm 0.06,0.62 \pm 0.06$, and $0.67 \pm 0.30)$, respectively. The administration of tamsulosin reduced the number of NVC $(0.57 \pm$ $0.42)$ and VT $(0.76 \pm 0.24)$ compared with L-NAME group. Co-treatment with tadalafil decreased the number of VT $(0.85 \pm 0.53)$ and MC $(0.76 \pm 0.22)$ compared with L-NAME group. The combination of tamsulosin with tadalafil improved the number of NVC $(0.56 \pm 0.18)$, VT $(0.97 \pm 0.52)$ and MC $(0.68 \pm 0.30)$ compared with L-NAME group. Conclusion: In rats with B00 induced by chronic nitric oxide deficiency, tadalafil did not cause impairment in detrusor muscle and seems to have an addictive effect to tamsulosin because the combination decreased non voiding contractions as well the number of micturition cycles.

\section{ARTICLE INFO}

\section{Key words:}

Urinary Bladder Neck Obstruction; tamsulosin [Supplementary Concept]; tadalafil [Supplementary Concept]; Urinary Bladder, Overactive

Int Braz J Urol. 2014; 40: 546-52

Submitted for publication:

October 15, 2013

Accepted after revision:

March 22, 2014

\section{INTRODUCTION}

There is now compelling evidence supporting a role for nitric oxide (NO)/cyclic guanosine monophosphate (cGMP) signaling pathways in the regulation of the micturition reflex (MR). Proteins of the NO/cGMP signaling pathway have been identified in the human lower urinary tract (LUT), suggesting a potential role in the physiology of bladder $(1,2)$. Acti- vation of the NO-cGMP signaling pathway generally results in relaxation of urethra and urethral sphincter, as well as of detrusor smooth muscle (DSM) (3).

A study showed that 4-week treatment with the NO synthase blocker L-Nitroarginine methyl ester (L-NAME) causes in vitro DSM supersensitivity to muscarinic agonists via increase in the levels of [H3]-inositol- phophate, accompanied by reduction of 33 -adrenoreceptor mediated DSM relaxations (4). 
Recently, studies addressing the effect of phosphodiesterase type-5 inhibitors (PDE5i) on LUTS, alone or in combination with alpha-blockers have been published (5-8). Initially, the rationale for the use of PDE5i in the treatment of lower urinary tract symptoms (LUTS) was based on demographic data showing the frequent occurrence of both erectile dysfunction (ED) and LUTS in men as they age (9). It has been shown that patients with ED treated with PDE5i experience improvement not only in ED symptoms but also in LUTS (10). As a consequence of these population studies, high level of evidence studies have emerged that clearly shows improvement in LUTS after treatment with PDE5i (11-13). Despite that, only few experimental studies have assessed the effect of this combination in the lower urinary tract.

It has been debated if PDE5i causes impairment of detrusor muscle because it ameliorates LUTS without change maximum flow in clinical studies. Additionally, it has been also discussed what is the better approach to patients with $\mathrm{BPH}$ with LUTS refractory to alpha-blocker. Change to PDE5i or combine alpha-blocker with PDE5i?

The aim of this study was to define if tadalafil causes detrusor muscle impairment and to observe the effect of combination of tadalafil with tamsulosin on the lower urinary tract of rats with bladder outlet obstruction (B00) induced by chronic nitric oxide deficiency.

\section{MATERIALS AND METHODS}

\section{Animals}

The study was approved by the Animal Research Ethics Committee. In the experiment 31 male adult Wistar rats weighing 275-330g were used.

\section{Experimental Groups \\ Thirty-one rats were randomized to five groups: \\ 1. Control $(n=6)$ : rats that received tap water alone for 4 weeks; \\ 2. L-NAME $(n=6)$ : rats that received L-NAME (20mg/rat/day, given in the drinking water for four weeks);}

3. Tamsulosin $(n=6)$ : tamsulosin was given by oral gavage $(1 \mathrm{mg} / \mathrm{kg} /$ day $)$ and L-NAME in the drink water;

4. Tadalafil $(n=7)$ : tadalafil was given by oral gavage $(5 \mathrm{mg} / \mathrm{kg} /$ day) and L-NAME in the drink water;

5. Tamsulosin/Tadalafil $(n=6)$ : tamsulosin $(1 \mathrm{mg} / \mathrm{kg} /$ day $)$ and tadalafil $(5 \mathrm{mg} / \mathrm{kg} /$ day) were given by oral gavage, and L-NAME diluted in the drink water; Based on dosages used in other studies, L-NAME $(20 \mathrm{mg} / \mathrm{kg} /$ day) was administrated diluted in drinking water; tamsulosin (1 $\mathrm{mg} /$ $\mathrm{kg} /$ day) and tadalafil $(5 \mathrm{mg} / \mathrm{kg} /$ day) were administered by oral gavage for 30 days (14-16).

\section{Cystometry in Anesthetized Rats}

All animals were submitted to cystometrogram (CMG) at the end of treatment period.

The rats were anesthetized intraperitoneally with urethane $(1.2 \mathrm{~g} / \mathrm{kg})$. A $1 \mathrm{~cm}$ incision was made along the midline of the rat abdomen. The bladder was exposed and a butterfly needle (19G) was inserted into the bladder dome and connected to a pressure transducer and to an infusion pump. Before starting the cystometry, the bladder was emptied and waited for a period of 30 min. to equilibrate detrusor. Continuous cystometry (CMGs) was carried out by infusing saline into the rat bladder at a rate of $4 \mathrm{~mL} / \mathrm{h}$. The Power Lab v.5.0 System (ADInstruments, Australia) was used to signal acquisition.

The following parameters were assessed: number of non-voiding contraction (NVC), threshold pressure (TP) at which micturition began, the peak pressure (PP) during micturition, volume threshold (VT) that was calculated by the time needed for the first micturition $\mathrm{X} 4 \mathrm{~mL} / 60 \mathrm{~min}$., number of micturition cycles (MC) per minute and basal pressure (BP). NVC was considered as spontaneous bladder contraction $>4 \mathrm{mmHg}$ from the baseline pressure that did not result in a void. The urodynamic variables evaluated and the methodology used in the CMGs match those described in the literature (17). Detrusor overactivity was defined as increase of NCV or MC. Bladder outlet 
obstruction (B00) was considered as increased VT with normal or increased TP (18). Detrusor hypocontratility was defined as increased VT associated with decreased TP.

\section{Statistical analysis}

The distribution of the quantitative, continuous and discrete variables was analyzed with the Kolmogorov-Smirnov test. Mean values and standard deviations were calculated and submitted to parametric tests. The five groups were compared by analysis of variance (ANOVA) while pairwise comparisons were made with Turkey's multiple comparison tests. The level of statistical significance was 5\% ( $p<0.05)$. The software GraphPad Prism ${ }^{\circledR}$ version 5.00 for Windows ${ }^{\circledR}$ (GraphPad Software, San Diego, California, USA, 2007) was used for the statistical analysis.

\section{RESULTS}

Long-term administration of L-NAME resulted in significant increase in number of NVC $(1.04 \pm 0.22)$, VT $(1.86 \pm 0.35)$, and MC $(1.34 \pm$ $0.11)$ compared with control $(0.52 \pm 0.06,0.62 \pm$ 0.06 , and $0.67 \pm 0.30) ; \mathrm{P}=0.006, \mathrm{P}<0.001$ and $\mathrm{P}$ $=0.01$, respectively (Table- 1$)$.
Co-treatment with tamsulosin decreased the number of NVC $(0.57 \pm 0.42)$ when compared with L-NAME $(\mathrm{P}=0.006)$. Tamsulosin administration also resulted in significant decrease in VT $(0.76 \pm 0.24)$ compared with L-NAME group. The number of MC improve $(0.95 \pm 0.54)$, however compared with L-NAME the reduction observed was not significant.

Co-treatment with tadalafil markedly decreased VT $(0.85 \pm 0.53)$ as well the number of MC $(0.76 \pm 0.22)$, compared with L-NAME $(\mathrm{P}=0.01)$. Although the administration of tadalafil decreased the NVC $(0.66 \pm 0.20)$, the amount of effect observed was not significant when compared with L-NAME Group.

The combination of tamsulosin with tadalafil resulted in significant reduction in number of NVC $(0.56 \pm 0.18)$, VT $(0.97 \pm 0.52)$ and MC (0.68 \pm $0.30)$, compared with L-NAME ( $\mathrm{P}=0.006, \mathrm{P}<0.001$ and $\mathrm{P}=0.01$, respectively) (Figures 1, 2, and 3).

There were no significant differences between the groups in relation of PT, PP and BP (Table-1).

\section{DISCUSSION}

The effect of tamsulosin and tadalafil, alone and in combination, on rats with BOO induced

Table 1 - Administration of $\mathrm{N}^{\omega}{ }^{-}$-nitro--arginine methyl ester hydrochloride (L-NAME) to the Group 2 resulted in increased number of non voiding contractions, volume threshold and micturition cycles compared to control. Administration of tamsulosin significantly decreased the number of non voiding contractions and volume threshold. Tadalafil decreased the number of volume threshold and micturition cycles. The combination of tamsulosin with tadalafil reduces either variables (COMPARED TO L-NAME).

\begin{tabular}{lcccccc}
\hline Variables & $\begin{array}{c}\text { Group } 1(\mathrm{n}=6) \\
\text { Mean } \pm \mathrm{SD}\end{array}$ & $\begin{array}{c}\text { Group 2 }(\mathrm{n}=6) \\
\text { Mean } \pm \mathrm{SD}\end{array}$ & $\begin{array}{c}\text { Group 3 }(\mathrm{n}=6) \\
\text { Mean } \pm \mathrm{SD}\end{array}$ & $\begin{array}{c}\text { Group } 4(\mathrm{n}=7) \\
\text { Mean } \pm \mathrm{SD}\end{array}$ & $\begin{array}{c}\text { Group } 5(\mathrm{n}=6) \\
\text { Mean } \pm \mathrm{SD}\end{array}$ & $\begin{array}{c}\text { P value } \\
\text { (ANOVA) }\end{array}$ \\
\hline NVC & $0.52 \pm 0.06$ & $1.05 \pm 0.23 \dagger$ & $0.58 \pm 0.43 \ddagger$ & $0.67 \pm 0.21$ & $0.56 \pm 0.19 \ddagger$ & 0.0101 \\
VT & $0.62 \pm 0.06$ & $1.86 \pm 0.35 \dagger$ & $0.76 \pm 0.24 \ddagger$ & $0.85 \pm 0.53 \ddagger$ & $0.97 \pm 0.52 \ddagger$ & 0.001 \\
PT & $26.67 \pm 4.50$ & $24.17 \pm 5.04$ & $26.71 \pm 4.11$ & $30.00 \pm 8.32$ & $28.83 \pm 2.14$ & 0.3637 \\
PP & $29.17 \pm 7.83$ & $27.50 \pm 4.76$ & $27.14 \pm 6.77$ & $29.67 \pm 2.94$ & $31.33 \pm 3.56$ & 0.6725 \\
MC & $0.68 \pm 0.31$ & $1.35 \pm 0.12$ & $0.96 \pm 0.54$ & $0.76 \pm 0.22 \ddagger$ & $0.68 \pm 0.30 \ddagger$ & 0.0101 \\
BP & $14.67 \pm 8.07$ & $18.83 \pm 3.13 \dagger$ & $16.14 \pm 6.96$ & $11.00 \pm 4.29$ & $11.00 \pm 4.82$ & 0.1135 \\
\hline
\end{tabular}

$\mathbf{1}$ = Control, $\mathbf{2}$ = L-NAME, $\mathbf{3}$ = Tamsulosin, $\mathbf{4}$ = Tadalafil and $\mathbf{5}$ = Tamsulosin/Tadalafil. NVC - non-voiding contraction, TP - threshold pressure, PP - peak pressure, VT - volume threshold, MC - micturition cycle and $\mathbf{B P}$ - basal pressure. SD - standard deviation, ANOVA - analysis of variance. The symbols $\dagger(\mathbf{P}<0.05)$ and $\neq(\mathbf{P}<0.05)$ denote statistically significant differences in relation to Group 1 and Group 2, respectively (Tukey's multiple comparison test). 
Figure 1 - Long term administration of $\mathrm{N}^{\omega}{ }_{\text {-nitro- }}$-arginine methyl ester (L-NAME) incresed the number of NVC, co-treatment with Tamsulosin and combination of Tamsulosin/Tadalafil reduce NVC.

Non Voiding Contractions (NVC)

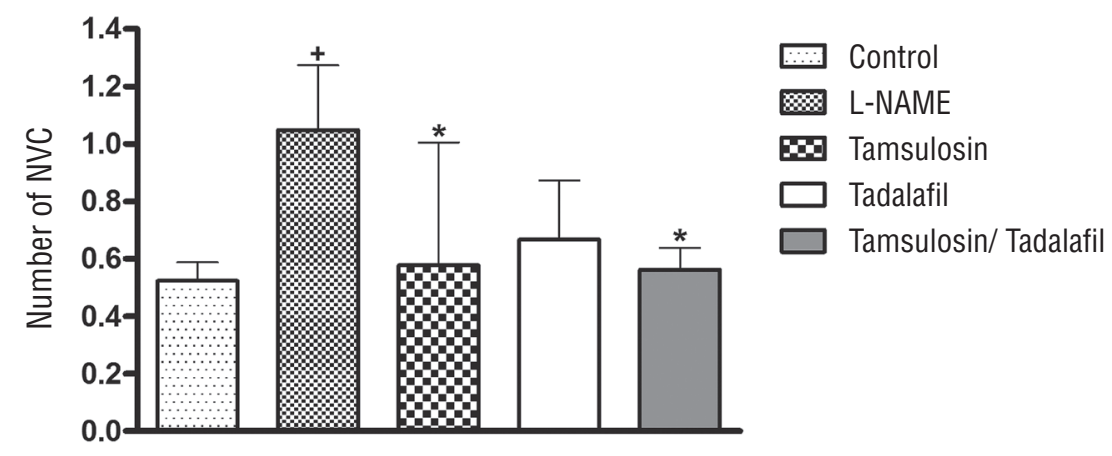

$+\mathrm{P}<0.05$ comparing L-NAME with control; ${ }^{*} \mathrm{P}<0.05$ comparing Tamsulosin and Tamsulosin/Tadalafil groups with L-NAME. (P refers to Tukey's multiple comparision test).

Figure 2 - Long term administration of $\mathrm{N}^{\omega}$-nitro- -arginine methyl ester (L-NAME) incresed volume thrshold (VT); c0-treatment with tamsulosin, tadalafil, and the combination of Tamsulosin/Tadalafil reduce VT.

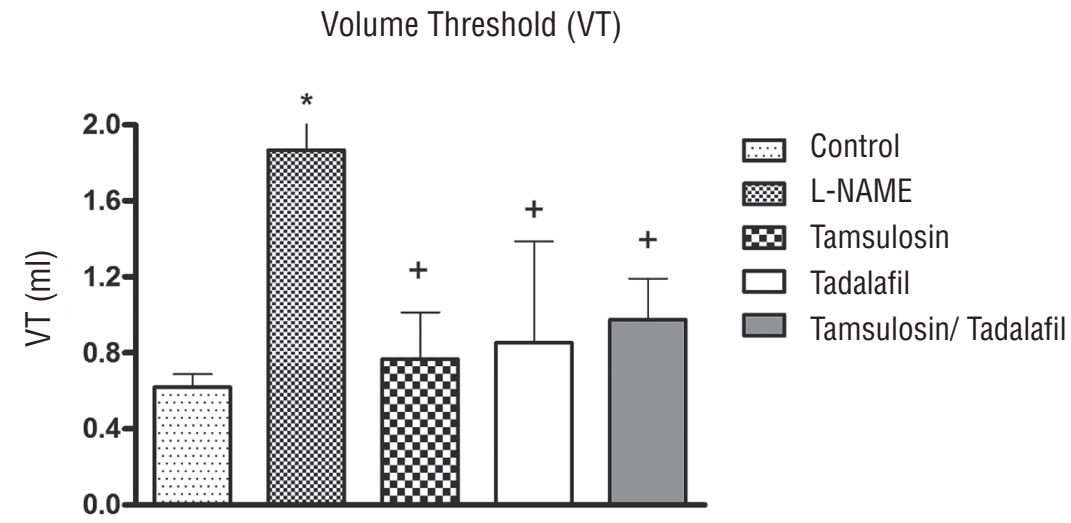

${ }^{*} \mathrm{P}<0.05$ comparing L-NAME with control; $+\mathrm{P}<0.05$ comparing Tamsulosin, Tadalafil and Tamsulosin/Tadalafil groups with L-NAME. (P refers to Tukey's multiple comparision test)

by chronic nitric oxide deficiency was evaluated in this study.

Initially, the chronic administration of L-NAME, a nitric oxide synthase (NOS) inhibitor, caused an increase in the number of NVC, VT, and MC compared with control. Increase in NVC and MC in experimental in vivo studies have been associated with DO (18). This finding was also similar to an organ bath study that evaluated bladder of rats submitted to chronic NO deficiency indu- ced by daily administration of L-NAME. An increased contractile response of the detrusor muscle to muscarinic receptors and reduced relaxation mediated by adrenergic receptors was noted (4). In this study, it was also observed an increase in VT in animals with chronic deficiency of NO similarly to a previous study (18). There are two theories that could explain this observation: increased urethral resistance or detrusor impairment. However, as micturition of the L-NAME rats had detrusor 
Figure 3 - Long term administration of $\mathrm{N}^{\omega}-$-nitro--arginine methyl ester methyl ester (L-NAME) incresed the number of MC, co-treatment with tadalafil and the combination of Tamsulosin/Tadalafil reduce MC.

Micturition cycles (MC)

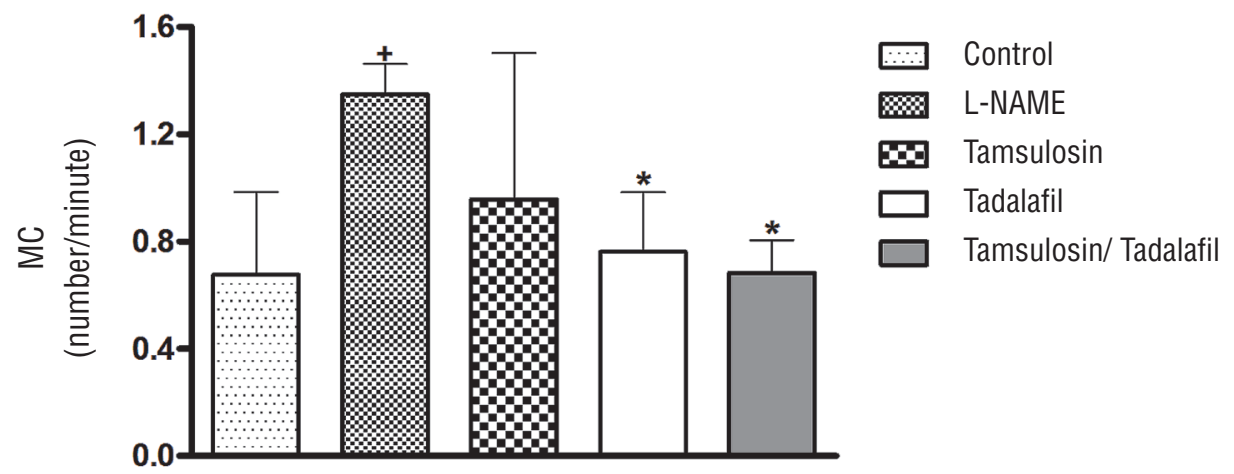

$+\mathrm{P}<0.05$ comparing L-NAME with control; ${ }^{*} \mathrm{P}<0.05$ comparing Tadalafil and Tamsulosin/Tadalafil groups with L-NAME. (P refers to Tukey's multiple comparision test)

pressure similar to control, it suggests an increased urethral resistance that is compatible with bladder outlet resistance.

When the animals with chronic deficiency of NO were treated with tamsulosin it was observed a reduction in VT. As previously known tamsulosin decreases smooth muscle contraction due to the alpha blocker action in prostate and urethra. Tamsulosin administration also improves the number of NVC and MC. However, only NVC was significant reduced compared with L-NAME Group. This finding corroborates with studies that have pointed the expression of alpha-1D adrenoceptors in rats with BOO (1). Therefore, it is a possible explanation to positive effect noted in the animals treated with tamsulosin on the filling phase. In one of these studies the effect of tamsulosin on the bladder function was investigated in conscious rats with bladder outlet obstruction induced by partial urethral ligation, and was concluded that premicturition contractions observed in obstructed rats were reduced with alpha-(1)-adrenoceptor antagonists (19). However, further studies are necessary to determine the mechanisms behind the effects of tamsulosin at bladder.

The administration of tadalafil reduced the number of NVC, VT and MC. However, compared with L-NAME, only the reduction of VT and MC was significant. The exact mechanism through which PDE inhibitors act in the lower urinary tract remains unclear. Nonetheless, there are several theories to explain it. The candidate mechanisms include pelvic atherosclerosis, autonomic hyperactivity, the calcium in independent Rho-kinase activation pathway and reduced NO levels (20). It is likely that there is an overlap between the roles of each of these candidate mechanisms. However, probably the hypothesis of the reduction of NO is the best explanation. This theory can be supported by the increase in the number of NVC, VT, and MC observed in the animals with chronic deficiency of NO in this study. Nitric oxide can activate guanylate cyclase, the enzyme that produces cGMP. The accumulation of intracellular cGMP triggers a cascade, leading to decreased intracellular calcium level and subsequent relaxation of smooth muscle cells. As previously known, the amount of cGMP results from the balance between production (NO) and degradation made by phosphodiesterase enzymes that hydrolyze and inactivate cyclic nucleotides. Thus, PDE5i increasing cGMP can probably explain the reduction in VT (decrease urethral resistance) and MC (relaxation of detrusor) observed in this study. This finding was comparable to other study that concluded that acute administration of sildenafil decreases the number of MC (18). As tadalafil did not decrease detrusor pressure (LP or PP) become 
evident that PDE5i do not cause impairment in detrusor muscle. This finding is important because it has been hypothesized that PDE5i could cause impairment in contractility of detrusor muscle.

It was also noted that the tadalafil seems to have an addictive effect to tamsulosin because beyond to improvement in VT, the combination markedly decreased NCV and MC. This finding in an experimental study could be a possible explanation why this combination was more effective to improve LUTS compared with the administration of tamsulosin or tadalafil alone in a randomized, double blind and placebo controlled clinical trial (8). PDE5i effect is likely to be due to a subsequent increase in cGMP resulting in relaxation of detrusor (NVC and MC) and urethral (VT) smooth muscle. In addition, a1-blockers are known to favor the cyclic cAMP-dependent signaling pathway involved in relaxation mediated by adrenoceptors. If cAMP-dependent signaling is favored in the presence of a $\alpha 1$-blocker, this could increase cGMP levels initially stimulated by tadalafil, which had until then remained functionally silent. Such positive cross-talk mechanism between cGMP and cAMP signaling previously described in other systems, could be the origin of the enhanced relaxant effect of the combination (20-23).

To our knowledge, this is the first experimental study that evaluated the effect of chronic orogastric administration combination of tamsulosin and tadalafil on the urinary tract of rats with BOO induced by L-NAME using CMG.

\section{CONCLUSIONS}

In rats with bladder outlet obstruction induced by chronic nitric oxide deficiency, tadalafil did not cause impairment of detrusor muscle and seems to have an addictive effect to tamsulosin because the combination decreased significantly non voiding contractions as well the number of micturition cycles.

\section{ACKNOWLEDGEMENTS}

Fundação Cearense de Apoio ao Desenvolvimento Científico e Tecnológico - FUNCAP and National Counsel of Technological and Scientific Development - CNPq

\section{CONFLICT OF INTEREST}

\author{
None declared.
}

\section{REFERENCES}

1. Andersson KE, Arner A: Urinary bladder contraction and relaxation: physiology and pathophysiology. Physiol Rev. 2004; 84: 935-86.

2. Fathian-Sabet B, Bloch W, Klotz T, Niggemann S, Jacobs G, Addicks $\mathrm{K}$, et al.: Localization of constitutive nitric oxide synthase isoforms and the nitric oxide target enzyme soluble guanylyl cyclase in the human bladder. J Urol. 2001; 165: 1724-9.

3. Masuda H, Okuno T, Suzuki M, Kihara K, Goto M, Azuma $\mathrm{H}$ : Different distribution of nitric oxide synthase and soluble guanylyl cyclase activities in the detrusor and proximal urethra of the rabbit. J Urol. 2002; 168: 2286-90.

4. Mónica FZ, Bricola AA, Báu FR, Freitas LL, Teixeira SA, Muscará MN, et al.: Long-term nitric oxide deficiency causes muscarinic supersensitivity and reduces beta(3)adrenoceptor-mediated relaxation, causing rat detrusor overactivity. Br J Pharmacol. 2008; 153: 1659-68.

5. Wang C: Phosphodiesterase-5 inhibitors and benign prostatic hyperplasia.Curr Opin Urol. 2010; 20: 49-54.

6. Gacci M, Corona G, Salvi M, Vignozzi L, McVary KT, Kaplan SA, et al.: A systematic review and meta-analysis on the use of phosphodiesterase 5 inhibitors alone or in combination with $\alpha$-blockers for lower urinary tract symptoms due to benign prostatic hyperplasia. Eur Urol. 2012; 61: 994-1003.

7. Bechara A, Romano S, Casabé A, Haime S, Dedola $P$, Hernández $C$, et al.: Comparative efficacy assessment of tamsulosin vs. tamsulosin plus tadalafil in the treatment of LUTS/BPH. Pilot study. J Sex Med. 2008; 5: 2170-8.

8. Regadas RP, Reges R, Cerqueira JB, Sucupira DG, Josino IR, Nogueira $E A$, et al.: Urodynamic effects of the combination of tamsulosin and daily tadalafil in men with lower urinary tract symptoms secondary to benign prostatic hyperplasia: a randomized, placebo-controlled clinical trial. Int Urol Nephrol. 2013; 45: 39-43.

9. Braun M, Wassmer G, Klotz T, Reifenrath B, Mathers M, Engelmann U: Epidemiology of erectile dysfunction: results of the 'Cologne Male Survey'. Int J Impot Res. 2000; 12: 305-11.

10. Sairam K, Kulinskaya E, McNicholas TA, Boustead GB, Hanbury DC: Sildenafil influences lower urinary tract symptoms. BJU Int. 2002; 90: 836-9.

11. McVary KT, Monnig W, Camps JL Jr, Young JM, Tseng LJ, van den Ende G: Sildenafil citrate improves erectile function and urinary symptoms in men with erectile dysfunction and lower urinary tract symptoms associated with benign prostatic hyperplasia: a randomized, double-blind trial. J Urol. 2007; 177: 1071-7. 
12. Stief CG, Porst $H$, Neuser D, Beneke M, Ulbrich E: A randomised, placebo-controlled study to assess the efficacy of twice-daily vardenafil in the treatment of lower urinary tract symptoms secondary to benign prostatic hyperplasia. Eur Urol. 2008; 53: 1236-44.

13. Roehrborn CG, McVary KT, Elion-Mboussa A, Viktrup L: Tadalafil administered once daily for lower urinary tract symptoms secondary to benign prostatic hyperplasia: a dose finding study. J Urol. 2008; 180: 1228-34.

14. Daugan A, Grondin P, Ruault C, Le Monnier de Gouville AC, Coste H, Kirilovsky J, et al.: The discovery of tadalafil: a novel and highly selective PDE5 inhibitor. 1: 5,6,11,11a-tetrahydro-1H-imidazo[1',5':1,6]pyrido[3,4-b] indole-1,3(2H)-dione analogues. J Med Chem. 2003 9; 46: 4525-32.

15. Ribeiro MO, Antunes E, de Nucci G, Lovisolo SM, Zatz R: Chronic inhibition of nitric oxide synthesis. A new model of arterial hypertension. Hypertension. 1992; 20: 298-303.

16. Kang HE, Bae SK, Yoo M, Lee DC, Kim YG, Lee MG: Interaction between udenafil and tamsulosin in rats: noncompetitive inhibition of tamsulosin metabolism by udenafil via hepatic CYP3A1/2. Br J Pharmacol. 2009; 156: 1009-18.

17. Tsukimi Y, Mizuyachi K, Matsumoto H, Sato M, Ng B, Tajimi M: Mechanism of action by which aspirin alleviates detrusor hyperactivity in rats. J Pharmacol Sci. 2004; 95: 101-7.
18. Reges R, D’Ancona C, Mônica F, Antunes E: Effect of acute administration of sildenafil to rats with detrusor overactivity induced by chronic deficiency of nitric oxide. Int Braz J Urol. 2013; 39: 268-75.

19. Ohtake A, Ukai M, Saitoh C, Sonoda R, Noguchi Y, Okutsu $\mathrm{H}$, et al.: Effect of tamsulosin on spontaneous bladder contraction in conscious rats with bladder outlet obstruction: comparison with effect on intraurethral pressure. Eur $\mathrm{J}$ Pharmacol. 2006 18; 545: 185-91.

20. Dmochowski R, Roehrborn C, Klise S, Xu L, Kaminetsky J, Kraus S: Urodynamic effects of once daily tadalafil in men with lower urinary tract symptoms secondary to clinical benign prostatic hyperplasia: a randomized, placebo controlled 12-week clinical trial. J Urol. 2010; 183: 1092-7.

21. Oger S, Behr-Roussel D, Gorny D, Lebret T, Denoux Y, Alexandre $\mathrm{L}$, et al:: Combination of alfuzosin and tadalafil exerts an additive relaxant effect on human detrusor and prostatic tissues in vitro. Eur Urol. 20100; 57: 699-707.

22. Tinel H, Stelte-Ludwig B, Hütter J, Sandner P: Pre-clinical evidence for the use of phosphodiesterase-5 inhibitors for treating benign prostatic hyperplasia and lower urinary tract symptoms. BJU Int. 2006; 98: 1259-63.

23. Pelligrino DA, Wang Q: Cyclic nucleotide crosstalk and the regulation of cerebral vasodilation. Prog Neurobiol. 1998; 56: 1-18.

\author{
Correspondence address: \\ Ricardo Reges, MD, PhD \\ Division of urology \\ Universidade Federal of Ceara \\ Rua Antonele Bezerra, 280 / 1501 \\ Meireles, Fortaleza, CE, 60160-070, Brazil \\ Telephone: +55 85 3262-3730 \\ E-mail: consultoriodeurologia@gmail.com
}

